\title{
Testosterone reactivity and identification with a perpetrator or a victim in a story are associated with attraction to violence-related cues
}

\author{
Roland Weierstall *, James Moran, Gilda Giebel, Thomas Elbert \\ University of Konstanz, Department of Psychology, Germany
}

\begin{abstract}
A B S T R A C T
Background: Recent field research has demonstrated that an attraction to aggressive behavior and cruelty is com mon among combatants and perpetrators involved in organized violence. The biological basis of this appetitive perception of aggression in humans has to date not been studied.

Aims: We examined testosterone as a potential hormonal moderator during induction of specifically appetitive aggressive behavior in the laboratory.

Method: To activate physiological responding related to appetitive aggression, 145 university students ( 72 women) listened to tape recordings of variants of a violent story. The perspective of the listener in the story was randomized between subjects. Participants were required to either identify as perpetrator, neutral observer, or victim. We assessed changes in saliva testosterone in response to the story. Subsequently, a series of pictorial stimuli (IAPS) with different valence ratings was presented and participants determined the length of viewing time with a button click. This viewing time for negative IAPS was assessed as a dependent variable indicating level of interest in violent scenes.

Results: Men identified themselves with the perpetrator more than women irrespective of the particular perspec tive presented by the story. Men who responded with an increase in saliva testosterone when adopting the perpe trator perspective chose to view the negative IAPS pictures for longer intervals than participants in other conditions or those who did not exhibit a release in testosterone.

Conclusions: Testosterone moderates attraction to cruel and violent cues in men, as indicated by extended deliber ate viewing of violence cues.
\end{abstract}

Keywords:

Appetitive aggression

Testosterone

IAPS pictures

Violent story

\section{Introduction}

Previous attempts to specify a taxonomy of aggression have dif ferentiated an impulsive, reactive form of aggression, associated with self defense, from a more controlled form of predatory aggres sion, as typically seen in predatory animals (Siegel, Roeling, Gregg, \& Kruk, 1999). Neuro scientific studies have also investigated aggres sion in terms of this differentiation in humans (e.g. Blair, 2004; Weiger \& Bear, 1988), as has clinical (e.g. Barker, Tremblay, Nagin, Vitaro, \& Lacourse, 2006; Dodge, Lochman, Harnish, \& Bates, 1997; Vitiello \& Stoff, 1997), and sociological research (Stein, 2000). Though these approaches have yielded many insights, these earlier classifications could not account for the possibility that hedonic impulses might motivate human aggressive behavior. This paper attempts to examine aggression in a laboratory setting as a poten tially arousing and rewarding phenomenon. We define this as 'appe titive aggression', as opposed to an impulsive, reactive or 'facilitative'

* Corresponding author at: Department of Psychology, University of Konstanz, P.O. Box 5560, 78457 Konstanz, Germany. Tel.: + 49753188 4065; fax: + 497531884601. E-mail address: roland.weierstall@uni-konstanz.de (R. Weierstall). aggression, and attempt to further examine the potential role of tes tosterone as a biological marker of this behavior.

The primary evidence for this work comes from fieldwork in crisis areas. A great deal of work in this area indicates that appetitive impulses are a major motivation underlying aggressive behavior. In interviewing more than 2500 soldiers in various crisis regions, we found that combatants report that committing violence became easier and enjoyable after only one or two repetitions (Elbert, Weierstall, \& Schauer, 2010; Weierstall \& Elbert, 2011, see also Maclure \& Denov, 2006). Higher appetitive aggression was associated with higher attained rank and increased likelihood of demobilized sol diers rejoining armed groups. Additionally, higher appetitive ag gression seemed to have a protective effect against the likelihood of developing posttraumatic stress disorder (PTSD) in a variety of different cultural groups, such as Rwanda (Weierstall, Schaal, Schalinski, Dusingizemungu, \& Elbert, 2011), Uganda (Weierstall, Schalinski, Crombach, Hecker, \& Elbert, 2012), the DR Congo (Hecker, Hermenau, Maedl, Elbert, \& Schauer, 2012) and German WWII veterans (Weierstall, Huth, Knecht, Nandi, \& Elbert, 2012).

The concepts appetitive vs. defensive or facilitative aggression are based upon fundamental approach/avoidance motivational concepts of Lang, Bradley, and Cuthbert (1997). Aggressive behavior can either 
be a self defensive response to perceived threat by an aggressor (with drawal), or it may result from an intrinsically rewarding act (approach) (Elbert et al., 2010; Weierstall \& Elbert, 2011). The two systems react differently to situations and stimuli encountered in war. Thus, the sound of gunfire, smell of smoke, sight of blood, can evoke the defense cascade of freeze flight fight fright faint, which with repeated activa tion forms a 'fear network', in which the various sensory, behavioral, cognitive and emotional reactions to fearful stimuli become chronically primed, and at their most result in the symptoms of PTSD. Alternately, these stimuli can be perceived as exciting, evoking a fundamental 'hunt ing network', characterized by arousal and reward related reactions to stimuli. We hypothesize that these fundamental systems are not limited to crisis regions, where laws and moral taboos are broken down, but manifest themselves in a variety of ways in all societies, for example through the enjoyment of competitive sports or violent media. The functionality of appetitive aggression, such as its protective effect against trauma disorders could be interpreted in evolutionary terms, as more theoretical papers that emphasize that the ability to hunt con veyed survival and reproductive advantages (Daly \& Wilson, 1996, Duntley \& Buss, 2005) and that it was necessary to appreciate or even enjoy stimuli associated with the arduous and often dangerous task of hunting and killing (Nell, 2006).

Testosterone is a likely candidate as a biological marker of appetitive aggression, as it (a) is a potent developmental, even prenatally active modifier of brain function and the masculinization of the brain (Knickmeyer \& Baron Cohen, 2006) and (b) has been associated with both aggression and also reward mechanisms. Testosterone's association with reward systems in the brain has been demonstrated in animal and human research. Testosterone has been shown to be rewarding in rats in conditioned place paradigms (Alexander, Packard, \& Hines, 1994; Arnedo, Salvador, Martínez Sanchis, \& Pellicer, 2002; De Beun, Jansen, Slangen, \& Van De Poll, 1992), and in oral self administration paradigms (Johnson \& Wood, 2001; Wood, 2002). In humans, steroid abusers show addiction like reactions to self administered testosterone (Brower, 1992; Brower, Blow, Young, \& Hill, 1991; Peters \& Wood, 2005; Wood, 2008), as well as increased rage, irritability and aggressive behavior (Choi, Parrott, \& Cohen, 1990; Parrott, Choi, \& Davies, 1994; Su et al., 1993). People with either medically mediated or natural abnormalities in testosterone show corresponding salient changes in aggressive behavior. Tetra hydrocannabinol (THC) has an anti androgenic effect, and is associ ated with a reduction of aggression in violent adolescent males (Renfrew, 1997; Tedeschi \& Felson, 1995). Transsexuals, either male to female, or female to male, report increases in characteristic opposite sex behaviors with the administration of the corresponding hormones, including aggression (Van Goozen, Cohen Kettenis, Gooren, Frijda, \& Van Der Poll, 1995).

Various experiments in microeconomics find effects of testosterone in competitive games where players can deceive and punish others financially, e.g. the Ultimatum Game or the Point Subtraction Aggres sion Paradigm (PSAP) (see Carré, McCormick, and Hariri (2011), for review). Higher testosterone is associated with an increased inclination to punish, reject unfair offers (Carré, Putnam, \& McCormick, 2009), and the desire play another competitive game vs. a non competitive game after losing a previous game (Mehta \& Josephs, 2006).

Though these results are compelling, it is necessary to design a labo ratory experiment that more directly evokes physical appetitive aggres sion observed in the field. Aggression has been induced in a variety of ways in a laboratory setting. However, many use paradigms that are more likely to induce facilitative aggression, by e.g. using frustration, threat (unpleasant stimuli e.g. electro shocks, cold water), or insults from the experimenter (Anderson \& Bushmann, 1997; Richtelin, Richardson, \& Mason, 2010). Other experiments have used media vi olence to induce aggression, such as computer games (Bluemke, Friedrich, \& Zumbach, 2009) and violent films (Bushmann, 1995; Linz, Donnerstein, \& Adams, 1989). Although these potentially stimulate appetitive aggression, they do not distinguish subtypes of aggression, complicating outcomes. An experiment from Klinesmith, Kasser, and McAndrew (2006), uses a paradigm more closely related to physical aggression. They found that handling a gun, as opposed to another toy caused an increase in testosterone, which had a partially mediating effect on a subsequent task provoking aggressive behavior.

In this study, we attempted to explicitly test the relationship be tween an evoked form of appetitive aggression and testosterone release, using a paradigm that is sufficient to induce an emotional state compa rable to the one that can be found among combatants in field studies. We have created a violent story, describing a scene in which a soldier viciously beats a farmer, focusing on the detailed experiencing of vio lence. The use of emotional stories is a well established paradigm in psychology and has proven its validity to evoke emotional responses (e.g. Cahill, Biabinsky, Markowitsch, \& McGaugh, 1995; Cahill, Haier, Fallon, et al., 1996). Experimental conditions are defined by narrating the events from different perspectives: From the point of view of the farmer; from the point of view of the soldier; and from the point of view of a neutral observer. These stimuli reflect complementary elements of appetitive aggression and self defensive facilitative aggres sion, by having experimental participants take the point of view of either perpetrator or victim, respectively. The point of view of observer is intended as a control condition. The contrast of appetitive vs. facilita tive reactions, intended to activate hunting networks and fear networks respectively, also parallels the above mentioned approach/withdrawal motivational theory of Lang et al. (1997). Accordingly, the dependent variables are drawn from Lang, Bradley, and Cuthbert's (2008) Interna tional Affective Picture System (IAPS); a standardized set of pictures designed to tap these respective motivational systems and rated along the two different dimensions of valence and arousal. We asked partici pants to rate the IAPS stimuli in terms of valence and emotional arousal (Bradley, Codispoti, Cuthbert, \& Lang, 2001). By priming the participants before presentation of these pictures with the violent story and asking participants to take the point of view of either the perpetrator, victim or observer, we predicted that there will be systematic differ ences in the subsequent viewing times and ratings of the IAPS stimuli, particularly in the perpetrator group, revealing appetitive aggressive responses, i.e. longer viewing times for negatively valenced pictures.

\section{Method}

\subsection{Participants}

Participants were 145 university students ( 72 women). They re ceived financial compensation of 7 Euros for participation in the one hour experiment. The age ranged from 18 to 39 years (median of 22 in both groups) with no significant difference between sexes (Mann Whitney $U$ test: $z=.40, p=.694$ ). Ten participants were classified as smokers (i.e. more than 7 cigarettes per week). All par ticipants were instructed to refrain from eating for at least $1 \mathrm{~h}$ before participation. Five participants provided saliva samples that were in adequate for salivary assay. Moreover, two male participants were classified as outliers due to their viewing times in the IAPS free view ing time paradigm that exceeded two standard deviations from the group means (one from the neutral perspective group and one from the victim's perspective group) and excluded from the final data set. However, all analyses were also calculated with inclusion of the two outliers, which did not change the results. Thus, complete data were available for 138 participants ( 69 women). 41 of these women were on contraceptive medication. None of the participants reported being on any other medication or reported suffering from any neuro endocrinological, neurological or psychiatric disorder or any other general health problems. The University of Konstanz ethi cal review board approved the study. 


\subsection{Design and violent story}

We used a single factor design with the factor group and its three levels perpetrator's perspective, neutral perspective and victim's perspec tive. The perspective manipulation read to the participants was varied between groups. We used a narrated story to evoke a targeted emotion al response. In the scene, a soldier is walking through a forest during the afternoon and encounters a foreign farmer. Without any provocation, he beats up the farmer and leaves him behind seriously injured. The story was based on an eye witness report and chosen because it was thought to have the least connections with the personal experiences of our student population. In the story we focused on the different levels of experiencing and sensory information (e.g. noises from the forest floor, sensory impressions of the opponent, i.e. appearance, smell, sounds), thoughts, physiological reactions (e.g. heart beating) and con text information (e.g. time and place) are described in the stories. The length of the stories was comparable (perpetrator' perspective, 507 words; neutral perspective, 511 words; and victim's perspective, 497 words). The stories from the perpetrator's and victim's perspectives shared 433 words, while for the first 37 out of 42 (perpetrator) 43 (victim) sentences, only a single word was changed (e.g. 'my rifle' vs. 'his rifle'). 16 sentences were identical. The perpetrator's perspective describes the appetitive arousal of injuring the other person. The victim's perspective focuses on the fear responses of the farmer. The neutral perspective describes the experiences from both people in par allel to allow either identification with the perpetrator or the victim. In the neutral story, words like 'me' or 'his' were replaced by 'the soldier's' or 'the farmer's'. The stories were read out by a professional book narra tor and recorded for presentation in the experiment. The audio files were of comparable length (perpetrator's perspective, 4:04 min; neutral perspective, 4:02 min; and victim's perspective, 4:00 min).

The participants were randomly assigned to the three groups and participant gender was balanced between groups. The factor 'sex' was added as a between subject factor in the analyses. The stories were presented via headphones. An English translation of the three different stories is provided in Appendix A.

\subsection{Measures}

\subsubsection{Free viewing time and IAPS picture rating}

As a measure for approach behavior towards violence cues we assessed the free viewing time of negative IAPS pictures (Lang et al., 2008) showing mutilations and pictures of dead bodies. To avoid a bias towards an identification with different people on the pictures, none of the selected pictures showed a scenario with other persons than the victim. We presented ten negative as well as ten positive IAPS pictures that did not differ according to their arousal ratings in the IAPS norm data but were chosen to decisively differ in valence. ${ }^{1}$ Moreover, the stimuli were chosen so as not to differ in luminance or RGB color distribution. The pictures were presented in random order on a 17" computer screen. We used 'PsyScope X Build 53' software to create the presentation. Participants were instructed to rate the pictures according to valence and arousal. An individual picture would be pre sented on the screen and participants could view this for as long as they liked, ending the viewing time with a button click. Total viewing time of each picture was recorded. From the viewing times we calculat ed two mean viewing scores, one for the unpleasant/negative IAPS pic tures and one for the pleasant/positive IAPS scores. The mean negative IAPS pictures viewing time was used as the main outcome measure as an indicator for the attraction to violent stimuli. After each picture, a 9 point computerized version of the Self Assessment Manikin (SAM, Bradley \& Lang, 1994) was used for the examination of the emotional

1 The following pictures from the IAPS were used: pleasant $-2030,2303,4698,8033$ $8185,8179,8341,8370,8460$, and 8496; unpleasant $-6212,6520,6821,9163,9252$, 9253, 9265, 9428, 9433, and 9635. picture ratings. To investigate whether there were differences in the emotional ratings of the negative IAPS pictures, the variables IAPS valence and IAPS arousal were included in the analyses.

\subsubsection{Saliva testosterone change}

We assessed saliva testosterone both before and after the story using a Salivette collection device (Sarstedt). The Salivettes were stored in a fridge at $28{ }^{\circ} \mathrm{C}$ immediately after each trial. The samples were centri fuged within $24 \mathrm{~h}$ after the sample collection. For saliva collection, the Salivettes were spun at $3000 \times \mathrm{g}$ for $5 \mathrm{~min}$ at room temperature. The inner snap seal container and the cotton swap are comprised and the sa liva is collected at the bottom of the tube. The capped tubes were stored at $-40{ }^{\circ} \mathrm{C}$. Saliva samples were analyzed for testosterone concentra tions using competitive chemiluminescence immunoassays (LIA) with a sensitivity of $0.0025 \mathrm{ng} / \mathrm{ml}$ (IBL, Hamburg). As we were interested in the testosterone change between the first and second saliva samples to address our research question, we subtracted the first concentration from the second for every participant. Positive values therefore indicate an increase in saliva testosterone while listening to the story.

\subsubsection{SAM emotional state rating}

As we were interested in the extent to which the story influences the participant's mood, we assessed the participant's current emotional state after the presentation of the story. The participant's state valence and the participant's state arousal were assessed with a 9 point paper pencil version of the SAM (Bradley \& Lang, 1994).

\subsubsection{Identification with the protagonist}

Participants had to indicate to what extent they identified them selves with the protagonist or the opponent. Answers to the questions 1) 'To what extent did you identify yourself with the perpetrator?' and 2) 'To what extent did you identify yourself with the victim?' were recorded on a five point Likert scale ranging from ' 0 ' (not at all) to ' 4 ' (extremely) for the two dependent variables perpetrator identification and victim identification.

\subsubsection{Procedure}

After the participants gave informed consent, the experimenter ex plained the study protocol to the participants. The first saliva sample was taken prior to the presentation of the story. Participants had to chew on the Salivette cotton swab for at least $1 \mathrm{~min}$. They were seated at a desk during the presentation of the story. The computer screen remained black during the presentation of the story, which the partici pants heard via headphones. After presentation of the story, the second saliva sample was taken. While the participants were chewing on the cotton swab, they completed the emotional state rating as well as the two questions regarding the identification with the perpetrator or the victim. Afterwards, the participants completed the free viewing para digm. Participants were thoroughly briefed on the procedure of the free viewing paradigm prior to the beginning of the IAPS presentation and participants had the opportunity to ask questions beforehand. Par ticipants had to perform the free viewing task without any interruption to assure a valid assessment of the response time, which was carefully controlled by the experimenter. After the experiment, the participants were informed about the research questions that the study was de signed to test.

\subsection{Data analysis}

For group differences in our dependent variables, we calculated two way ANOVAs with the two between subject factors group and gender. We used linear regression analysis to explore the association between the prognostic variables and the main dependent variable free viewing time. Relations between the prognostic variables were calculated using Pearson correlation coefficients. The statistical modeling and analysis were carried out using R for Mac OSX Version 2.11.1 ( $\mathrm{R}$ Development 
Core Team, 2010). All other analyses were performed using SPSS 18 for Mac. Power analyses and calculations of effect sizes were performed with G*Power 3 for Mac (Faul, Erdfelder, Lang, \& Buchner, 2007).

\section{Results}

\subsection{Manipulation check: Identification with the perpetrator and victim}

To check whether or not our manipulation worked out, we first cal culated a multivariate ANOVA for the two dependent variables perpetra tor identification and victim identification and the two factors group and gender. In line with our theoretical assumptions one would expect an effect of group for both stories as well as an effect of gender at least for the perpetrator's perspective, where male participants should have higher scores. The results for the mean identification scores are displayed in Fig. 1a for the perpetrator identification and Fig. 1b for the victim identification.

For perpetrator identification, there was a main effect for the factor group $\left(F_{5,137}=14.77, p<.001, \eta_{p}{ }^{2}=.35\right)$ as well as for the factor gender $\left(F_{1,137}=16.82, p<.001, \eta_{p}{ }^{2}=.11\right)$, but no significant interac tion between both factors $\left(F_{2,137}=1.23, p=.296, \eta_{p}{ }^{2}=.02\right)$. Thus, all male participants identified themselves more with the perpetrator than female participants across groups. Moreover, participants who perceived the story from the perpetrator's perspective had the highest identification score. The lowest perpetrator identification scores were obtained for those participants who heard the story from the victim's perspective. Participants who heard the story from the neutral perspec tive, having a free choice between both perspectives, had intermediate identification scores. This result is in line with our hypothesis.

For the victim's perspective, there was also a significant main effect for the factor group $\left(F_{5,137}=9.05, p<.001, \eta_{p}{ }^{2}=.12\right)$ but no main ef fect for the factor gender $\left(F_{1,137}=.04, p=.852, \eta_{p}{ }^{2}=.00\right)$ and a trend for the interaction $\left(F_{2,137}=2.36, p<.01, \eta_{p}{ }^{2}=.03\right)$. As can be seen in Fig. 1b, there was a reversed effect between groups for the identification with the victim compared to the perpetrator identification. However, this is effect was mainly influenced by the female participants, while there was a trend that male participants showed comparable identifica tion scores across groups.

3.2. Testosterone release as a moderator for an attraction to violence in participants from the perpetrator perspective

To test our hypothesis that testosterone release predicts the free viewing time of the negative IAPS pictures, we regressed the free view ing time of the negative IAPS pictures on the salivary testosterone change in the subgroup of those participants with the perpetrators perspective. As we postulate that aggression is primarily appealing to men, we also added gender as a dummy coded variable to the analysis (' 0 ' for female and ' 1 ' for male participants), as well as the interaction between salivary testosterone change and gender. This interaction turned out to be significant $(\beta=.42, p=.038)$, while there was nei ther a main effect for the factor gender $(\beta=.18, p=.199)$ nor for the predictor salivary testosterone change $(\beta=-.10, p=.634)$. Thus, male participants who showed an increase in saliva testosterone during the story viewed the negative IAPS pictures for longer intervals than those who did not respond with a testosterone increase (Fig. 2).

Measuring differences in salivary testosterone response revealed a trend suggesting that men with perpetrator perspective show a relative increase of testosterone $(M=11.4 \mathrm{pg} / \mathrm{ml}, S D=54.6 \mathrm{pg} / \mathrm{ml})$, and women a relative decrease $(M=-16.7 \mathrm{pg} / \mathrm{ml}, S D=54.4 \mathrm{pg} / \mathrm{ml})$. However, a two tailed test of this testosterone response between the sexes did not reach significance, but indicated a trend as well $\left(t_{47}=\right.$ $1.80, p=.082, d=.52$ ). Moreover, the testosterone levels in males were higher than females prior to (males: $M=142.7 \mathrm{pg} / \mathrm{ml}, S D=$ $38.2 \mathrm{pg} / \mathrm{ml}$; females: $M=104.4 \mathrm{pg} / \mathrm{ml}, S D=39.0 \mathrm{pg} / \mathrm{ml}, t_{47}=3.48$, $p=.001, d=.99$ ) and after the story (males: $M=154.2 \mathrm{pg} / \mathrm{ml}$,
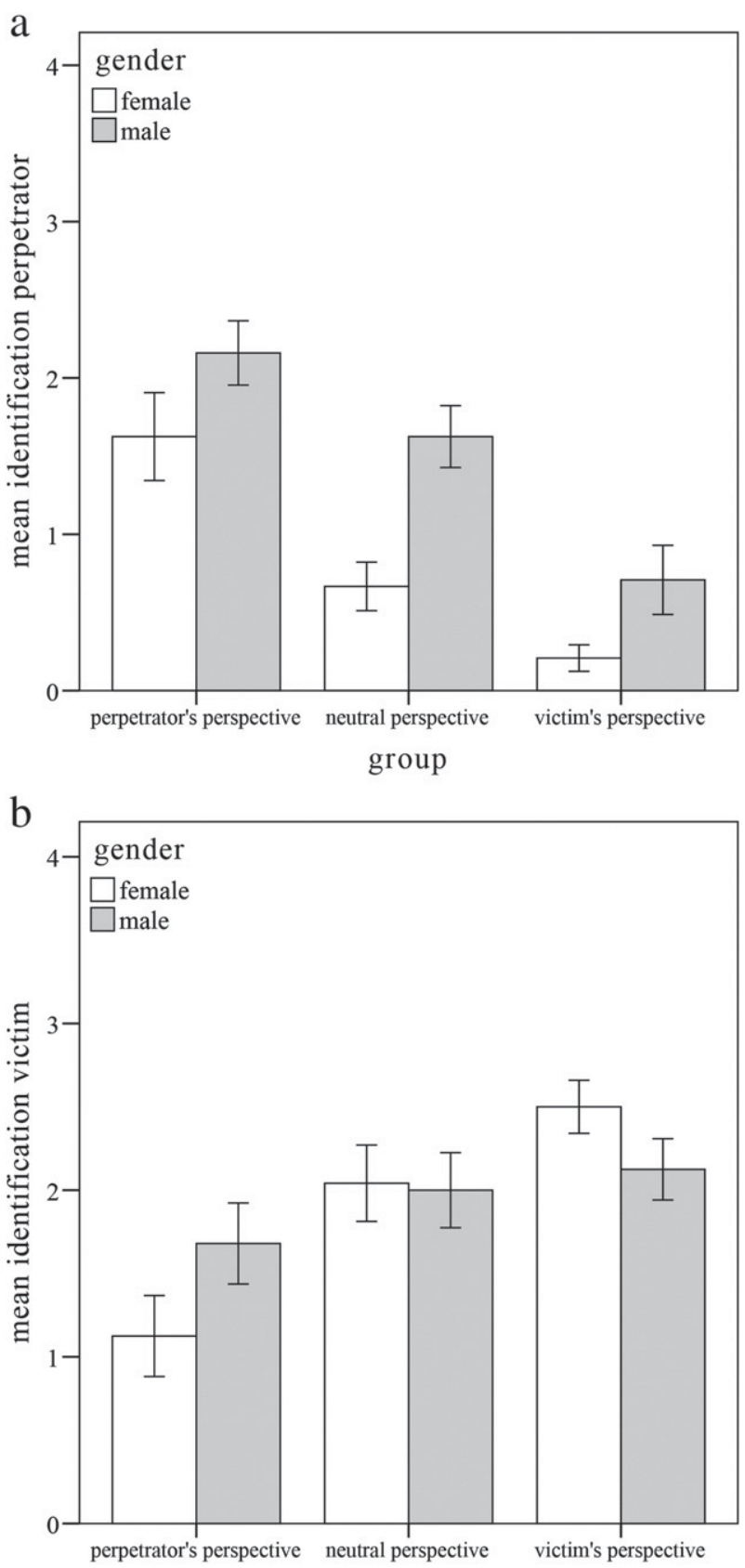

group

Fig. 1. Identification scores ( $M \pm S E$ ) for the perpetrator's (1a) and victim's perspectives (1b) depending on the two factors group and gender. Large values represent a high identification.

$S D=51.4 \mathrm{pg} / \mathrm{ml}$; females: $M=87.7 \mathrm{pg} / \mathrm{ml}, S D=33.4 \mathrm{pg} / \mathrm{ml}, t_{47}=$ $5.34, p<.001, d=1.53)$. The regression model that was significant for the negative IAPS picture viewing time $\left(F_{3,45}=3.16, p<.034\right)$ did not fit for the positive IAPS pictures $\left(F_{3,45}=1.42, p=.249\right)$.

\subsection{Predicting free viewing time from group, saliva testosterone change and identification scores}

We first calculated a univariate ANOVA for the dependent variable free viewing time and the two factors group and gender. We obtained no significant main effect for the factor group $\left(F_{5,137}=.43, p=.649\right.$, $\left.\eta_{p}{ }^{2}=.01\right)$, a main effect for the factor gender by trend $\left(F_{1,137}=3.33\right.$, $p=.07, \eta_{p}^{2}=.02$ ) as well as no significant interaction between both 


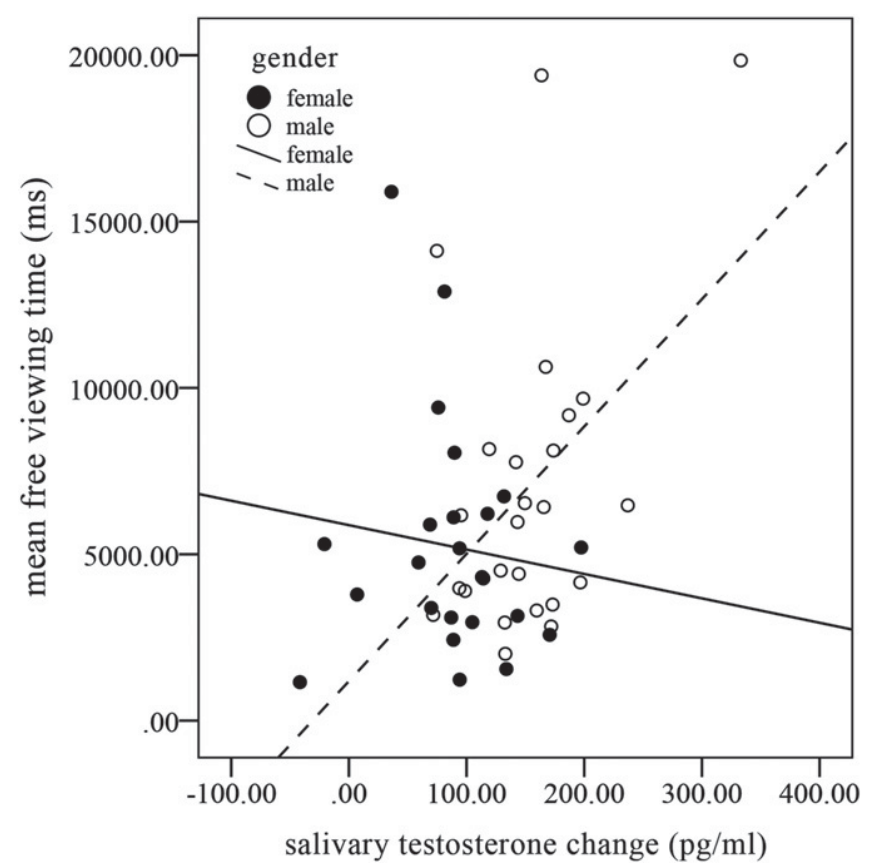

Fig. 2. Relation between the salivary testosterone release and the free viewing time for negative IAPS pictures. Only participants who listened to the perpetrator's perspective are displayed. Regression analyses revealed no significant relation for female participants, but a significantly more positive relation for male participants (see text for further details).

factors $\left(F_{2,137}=.29, p=.753, \eta_{p}^{2}=.00\right)$. However, as we obtained differences in the identification with the protagonists in the story between groups we tried to disentangle the relations between the variables. We therefore regressed the free viewing time on the predictor variables perpetrator identification, victim identification, and saliva testos terone change, four dummy coded variables for male and female partic ipants from the perpetrator's perspective group as well as male and female participants from the victim's perspective group and all possible two way interactions. Akaike information criterion (AIC, Akaike, 1987) was used for the selection of the best fitting model. The final model $\left(F_{5,131}=4.20, p=.001\right)$ is given in Table 1 and the relation between the different variables is displayed in Fig. 3.

There was a main effect for the identification with the perpetrator irrespective of the group. Thus, participants who reported a higher iden tification with the perpetrator in the story also showed more approach behavior towards pictures displaying mutilations and dead bodies. Moreover, the interaction effect we reported in our initial analyses was also present. Male participants from the perpetrator perspective group showed a higher attraction towards violence in relation to the

Table 1

Results from the linear regression analyses predicting free viewing time for negative IAPS pictures. Standardized beta-coefficients are displayed.

\begin{tabular}{|c|c|c|}
\hline & \multicolumn{2}{|c|}{$\begin{array}{l}\text { Free viewing time for } \\
\text { negative IAPS pictures }\end{array}$} \\
\hline & $\beta$ & $p$ \\
\hline Perpetrator identification & .26 & .008 \\
\hline $\begin{array}{l}\text { Victim perspective dummy } \\
\text { variable }\end{array}$ & .22 & .019 \\
\hline $\begin{array}{l}\text { Males perpetrator perspective } \\
\text { dummy variable }\end{array}$ & .08 & n.s. \\
\hline Saliva testosterone change & .01 & n.s. \\
\hline $\begin{array}{l}\text { Males perpetrator perspective } \\
* \text { Saliva testosterone change }\end{array}$ & .22 & .011 \\
\hline Model & $F_{5,131}=4.20$ & .001 \\
\hline
\end{tabular}

neutral perspective that served as a reference category when they released testosterone while listening to the story, however, this testos terone effect was limited to participants from the perpetrator perspec tive. Additionally, we found a main effect for participants from the victim perspective group, irrespective of their gender. Participants from this group also had longer viewing times. From a statistical point of view, the proposed model fulfilled all necessary quality criteria (maximum VIF 1.4; maximum Cook's $d$ of .94; Levene test for homo geneity of variances between groups: $F_{2,134}=1.17, p=.313$; $f^{2}=$ .16 , power $(1-\beta)=.96)$.

\subsection{Identification with the protagonist and its relation to emotional ratings}

To identify the relation between the perpetrator identification and victim identification with the emotional ratings of the pictures and the ratings of the emotional state, we calculated all zero order Pearson's correlations (Table 2).

As can be seen in the correlation pattern, the IAPS arousal ratings are crucial. They are higher in those who identify with the victim and lower in those who identify with the perpetrator. Moreover, identification with the victim induces a negative emotional state, while the identifica tion with the perpetrator leaves it unaffected.

\section{Discussion}

This experiment was an attempt to examine the concept of appeti tive aggression, hitherto observed in clinical field studies, in a laboratory setting. A simple story narrated to the participants from different per spectives yielded several interesting findings. The dependent variable of viewing time of negative IAPS pictures was not directly influenced by the perspective manipulation. However, male participants taking on the perspective of the perpetrator who also showed an increase in salivary testosterone did show a longer viewing time for negative IAPS pictures. Thus, the stimuli seemed to evoke an appetitive approach response, measured in terms of viewing times of IAPS pictures in men; though the extent of this effect varies across men. Additionally, testos terone was revealed as a moderator of this association. Thus testoster one is at least associated with appetitive aggressive responses in men. This model held specifically for negative IAPS pictures, and not for positive or neutral ones. Examining the patterns of identification with the perpetrator, victim and observer perspectives yielded more nu anced interactions between the variables. The perspective manipula tion, where the participant is required to identify with the perpetrator, victim or an outside observer, was successful, in that people in the perpetrator condition identified most strongly with the perpetrator, people in the victim condition identified most strongly with the victim and people in the observer category showed intermediate patterns of identification. However, in accord with the theory of appetitive aggres sion being a specifically male phenomenon (Elbert et al., 2010), male participants showed an overall increased identification with the perpe trator compared to female participants. Women showed an overall increased identification with the victim across all conditions.

Factoring the variable of perpetrator identification into the total model revealed that level of identification with the perpetrator predict ed more appetitive responses, operationalized as longer viewing times of negative IAPS pictures. As with the initial analysis, men in the perpe trator condition who additionally showed an increased testosterone release also showed longer viewing times of specifically negative IAPS pictures.

Priming an appetitive response in people did not lead to a simple group increase in testosterone but rather showed testosterone to have a moderating effect within experimental groups. This is in accord with a general trend in testosterone research to examine individual differ ences in testosterone response to experimental manipulation. Carré et al. (2011) state that the average change in testosterone between ex perimental groups is less meaningful than the individual differences 


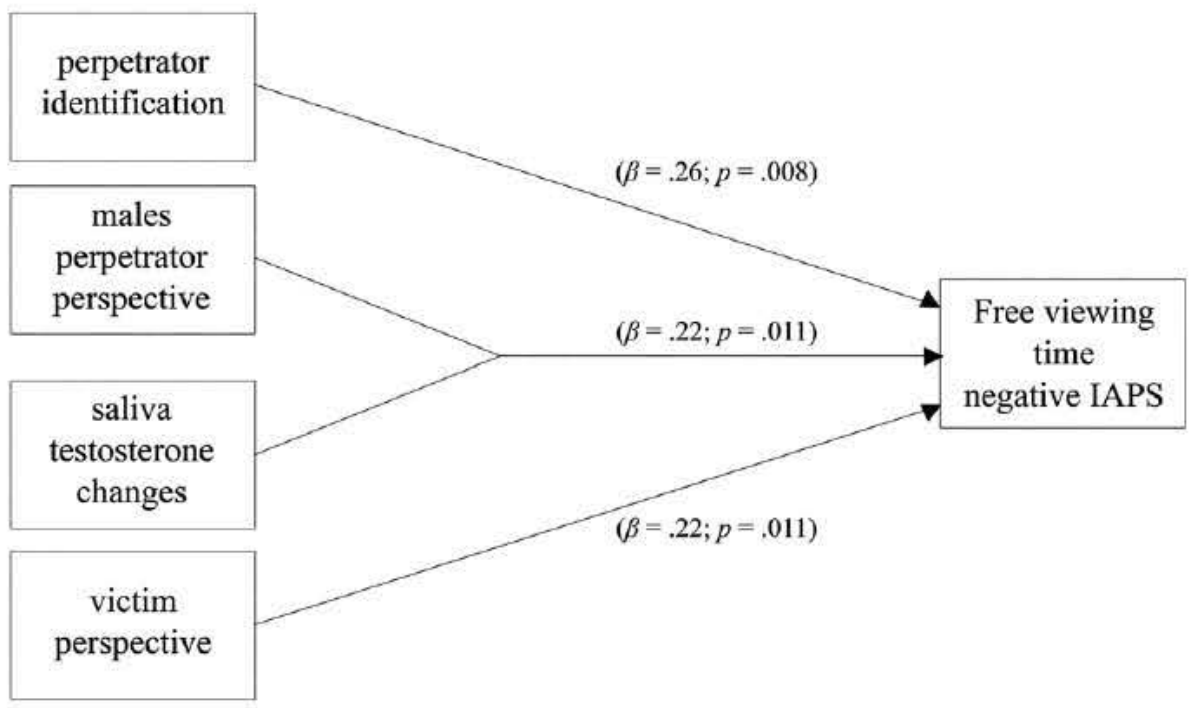

Fig. 3. Path model displaying the interactions between the group membership, the identification with the perpetrator in the story and the testosterone release during the story for the prediction of the free viewing time for negative IAPS pictures (see text for details) for the prediction of free viewing time for negative IAPS pictures. The neutral perspective served as the reference category for the group dummy variables. Perpetrator identification represents the identification with the perpetrator in the story irrespective of group membership. Males perpetrator perspective represents male participants only from the group that listened to the story of the perpetrators' perspective.

within groups. For example, in economics experiment games such as the PSAP, testosterone changes in response to a victory were correlated with subsequent reactive aggression measures only in men with high dominance (Carré et al., 2009); in another study, men were assigned to compete in a game, with half losing and the other half winning. The differences in testosterone between winners and losers were in itself not significant, and the variance was very large. However, among men who lost a competition, their decision to participate in a further compe tition was predicted primarily by their changes in testosterone; those with higher testosterone increases wanted to compete, those with lower levels wanted a non competitive task (Mehta \& Josephs, 2006). Individual differences can also be seen in socially anxious men who lost a rigged competition (Maner, Miller, Schmidt, \& Eckel, 2008). They showed a decrease in testosterone in response to losing that was not present in non socially anxious men.

The clinical findings of our research suggest that there are indeed individual differences determining whether a child soldier will become someone capable of hunting and killing human beings or not. Reports from child soldiers suggest that certain groups of children seem to be easily capable of being transformed into 'cruel people' (Elbert et al., 2010). This experiment supports the idea that testosterone indicated moderation of appetitive aggression, it will be necessary for future field research to test whether ex combatants with higher measured levels of appetitive aggression also show correspondingly higher levels of testosterone. Furthermore, if this is the case, then it would be interesting to further investigate other associated personality and developmental variables that could be related to the higher levels of appetitive aggression.

A higher identification with the victim also predicted an increased viewing time for negative IAPS pictures. Based purely on the variables of perpetrator vs. victim identification, both produce longer viewing times for the negative IAPS pictures. Examining the participants' ratings of valence and arousal levels of the negative IAPS pictures suggests that those people identifying with the victim were reacting in a fundamen tally different way to the negative IAPS pictures than those people who identified with the perpetrator. People with a stronger identifi cation with the victim saw the pictures as more arousing and more negative, whereas people with higher levels identification with the perpetrator showed no such increase in arousal or negative valence.

Thus, perspective taking in the processing of a violent scene, either perpetrator or victim, seem to affect the perception and processing of violence cues. We suggest that stronger primed perpetrator identifica tion provokes the activation of a hunting network, that is the set of physiological, behavioral, cognitive and emotional responses associated with appetitive aggression (Elbert et al., 2010). The activation of this is reflected in a greater propensity to look at violent images, without an in crease in alarm or an increase in repugnance. The person is after all, in a hunting mode, and requires command of his own reactions. In contrast, priming an association with the victim activates a complementary fear network, in which the person is more attuned to interpret the same en vironmental stimuli as threatening (Elbert, Rockstroh, Kolassa, Schauer, \& Neuner, 2006). In line with Bradley et al. (2001), we hold that this

Table 2

Correlations between emotional ratings and perspective taken in the story.

\begin{tabular}{|c|c|c|c|c|c|}
\hline & Victim identification & State valence & State arousal & IAPS valence & IAPS arousal \\
\hline $\begin{array}{l}\text { Perpetrator identification }(M=1.2 \pm S D=1.2) \\
\text { Victim identification }(M=1.9 \pm S D=1.1) \\
\text { Participant's state valence }(M=5.3 \pm S D=1.4) \\
\text { Participant's state arousal }(M=5.4 \pm S D=1.6) \\
\text { Negative IAPS valence }(M=1.1 \pm S D=0.8) \\
\text { Negative IAPS arousal }(M=5.2 \pm S D=1.6)\end{array}$ & $r_{p}=32^{\text {**** }}$ & $\begin{array}{l}r_{p}=.12 \\
r_{p}=.23^{* *} \\
-\end{array}$ & $\begin{array}{l}r_{p}=.01 \\
r_{p}=.13 \\
r_{p}=.22^{* *} \\
-\end{array}$ & $\begin{array}{l}r_{p}=.13 \\
r_{p}=.12 \\
r_{p}=.14 \\
r_{p}=.08 \\
-\end{array}$ & $\begin{array}{l}r_{p}=.20^{*} \\
r_{p}=24^{* * *} \\
r_{p}=.17^{*} \\
r_{p}=27^{* * * *} \\
r_{p}=.27^{* \text { ***k }} \\
\end{array}$ \\
\hline
\end{tabular}

Note: asterisks indicate level of significance.

${ }^{*} p<.05$.

*** $p<.01$.

**** $p<.001$ 
fear associated initial perception of a negative IAPS picture corresponds to the initial perception of a possible threat in the environment, prompting the activation of a freezing mechanism, where the organism has a heightened perception of their environment and remains motion less. This attention capturing mechanism has been described in different psychological studies that reported prolonged responses after the pre sentation of threat stimuli (e.g. Fox, Russo, Bowles, \& Dutton, 2001; Yiend \& Matthews, 2001). Consequently, the negative pictures in our study might produce a prolonged viewing time to freeze, analyze the scene and estimate the relevance of the threat, when the participant identifies with the victim as threat stimuli become salient to them. However, the opposite effect has been reported as well with people very high in anxiety, who one would expect to have an intensely primed fear network and show an opposite response when presented with un pleasant stimuli. For example, chronic anxiety patients view phobic stimuli for shorter periods of time, rather than longer periods (Hamm, Cuthbert, Globisch, \& Vaitl, 1997). We hold that the difference between a healthy participant's reaction to a violent stimulus after being primed as a victim can be explained in terms of the activation of the defense cas cade. Here, a sequence of qualitatively distinct behavioral reactions to threat stimuli, arranged in order of freeze flight fight fright faint can be activated, someone with an anxiety disorder would have a chronical ly active reaction to threat, bypassing the earlier stages of the defense cascade, to go directly to flight mode (Schauer \& Elbert, 2010). The assessment of personality traits from the anxious avoidant spectrum might be useful to explain further variance from the viewing time of negative high arousing pictures and should be applied in a future study.

Our stimuli were designed to tap the sort of cruelty and enjoyment of violence documented in our field studies, asking participants to put themselves in the position of a perpetrator or victim in an incident very like those experienced by patients in our field studies. One could argue that the story actually evoked facilitative aggression rather than a specifically appetitive aggression. Distinguishing the two forms of ag gression could be made more difficult owing to the fact that instrumen tal and facilitative forms of aggression often co occur (Barker et al., 2006). However, we postulate that facilitative aggression belongs to a fundamentally defensive motivational system, corresponding to the fight section of the defense cascade, and is fundamentally separate from appetitive aggression. Crucially, it is important to note that our ap petitive aggressive condition showed comparatively low arousal ratings for negative IAPS pictures. This argues for a controlled appetitive reac tion, rather than a facilitative response, which is generally characterized as having a high arousal (Blair, 2004; Vitiello \& Stoff, 1997).

Another potential objection is the investigation of ordinary students from a peaceful society to measure a phenomenon hitherto witnessed in a war torn society. For the future research on human aggression and the perception of violence, the results from this study have an essential im plication: Based on the two motivational systems that can direct human behavior, it seems reasonable to differentiate two forms of aggression within both ordinary people and war affected people in line with the underlying emotional and motivational state. One form is associated with a highly arousing and negative affective state like rage, fear or hos tility and the motivational trajectory of avoiding the actual state. The other form is associated with approach behavior and the motivational trajectory of getting into a positive but also arousing state, such as atten tiveness, engagement, and pleasure. This theoretical distinction could not only help refocus empirical studies of human aggression, but would also be a useful tool in clinical practice for understanding a person's motivation to show aggressive behavior in a given situation. This result is in line with other research showing that aggression is a functional facet of human behavior in general, not limited to a minority of deviant people (e.g. Duntley \& Buss, 2011). Though our theory pre dicts that appetitive aggression is unleashed in social contexts where social taboos against violence are broken, we posit that this same ten dency is also reflected in peaceful societies in the form of playing and watching competitive sports, and violent computer games.
One result that needs further attention is the nature of appetitive aggression in women. In this study, we show that men identified signif icantly more with the perpetrator and also experienced violent pictures as being more appealing. On the one hand, this result can be partially explained with gender typical difference in correlates of aggressive be havior, e.g. women being more anxious (Lewinsohn, Gotlib, Lewinsohn, Seeley, \& Allen, 1998). Girls are more socialized than boys to understand moral behavior primarily through empathetic understanding of others' suffering (Gault \& Sabini, 2000, Keenan \& Hipwell, 2005). A side effect of this could be a greater propensity to identify with the victim. This result also seems to be in line with the general consensus in aggression research that female aggression is qualitatively different with at least less overt physical cruelty (Bettencourt \& Miller, 1996; Eagly \& Steffen, 1996). However, the influence of gender stereotypical socialization pro cesses has been discussed as one explanation for the reported differ ences, rather than biological differences between both sexes (Archer \& Mehdikhani, 2003; Archer \& Parker, 1994). Additionally, the literature suggests that gender differences vanish for facilitative aggressive behav ior: Women being provoked or threatened also tend to show physical aggression. For appetitive aggression, gender differences have thus far not been investigated. We propose that this attraction to violence is a primarily male domain with a potentially specifically male biological preparedness (see also Elbert et al., 2010). Though our results are con gruent with this, a lot more research are required in the field and in the laboratory to clarify the respective influences of biological and social factors defining sex specific aggressive behavior.

\section{Conclusion}

In conclusion, the study shows that priming participants with appe titive violence has measurable effects on people's desire to view violent stimuli, and that this is moderated by testosterone release. This is specif ic to male participants, in accord with assumption that it is shaped by evolution to be a pre dominantly male biological prepared response mode. Future research on aggression should focus on the actual under lying emotional and motivational state, primarily indicated by aggres sion related emotional valence, as well as the resulting motivational trajectory that directs the behavior.

\section{Acknowledgment}

We appreciate the help of Simon Barton, Patricia Heppler and Jadin Murza with data collection. We also gratefully acknowledge the analysis of saliva samples by Professor Dr. Clemens Kirschbaum and his team. This research was supported by the DFG.

\section{Appendix A. Story variations}

\section{A.1. Perpetrator perspective}

It was a rainy autumn day. Fog lay over the fields, but the sun was bright behind the sheen of white fog. The drizzle came through my clothing and I shivered a little. I trod through the forest, feeling the soft leaves give way, and hearing the twigs snap underfoot. I was on the way from our camp back home, and was thinking happily about how I would soon see my wife again. I was pleasantly absorbed in these thoughts. After a few more meters I heard steps behind a ridge up ahead, and then saw a man emerge before me. This was the first and last time I would encounter him. He was a farmer. I could see his face. It was expressionless and unshaven. He wore an olive colored rain jacket and heavy, clay caked boots. As he came nearer I could smell the sweat and dirt of his body, he had obviously had a long day behind him. As I watched him, the experiences of the last few days went through my head again, as we attacked villages. This farmer reminded me of a man, who I had killed in his house after he tried to hide from us. My body began to shake. That intoxicating feeling came 
through me again. In such moments, my senses sharpened and I became aware of my own heavy breath. I saw the pictures before my eyes of those people we had chased until they were exhausted, their death rattle as their wounds bled out and they died. It excited me. That feeling that overwhelmed me at this moment is like nothing else. It was pure lust. In this moment I drew out my rifle and smashed the gunstock with full force against his jaw, which gave way with a dull moist crack. He dropped to his knees. His panicked and broken cry was the only thing that I could hear now apart from my breathing. My head was empty and clear. The only thing that came to my consciousness was the terrified look on his face and how I wanted to see more. His wide open eyes were filled with an indescribable blackness. I could not turn away from this sight if I had wanted to. Warm blood ran from his shattered face and I could see the hot breath climbing into the cold air. I had the feeling that every muscle fiber in my body was electrified. I felt ecstatic, as if I was on a powerful drug. Then I nothing could hold me back any longer. The butt of my rifle smashed into his body over and over again. He broke to pieces. Everything around me melted away in this moment. There was only him and me and nothing that could stop me. I felt the soft resistance of his flesh under his clothing and the way the bones broke. He could not defend himself was easy to hit. He was absolutely still for a long time before I let off. I saw his face one more time. His hair and his clothing were soaked with blood. Everything around me was still. I walked away from him as he lay there, but then turned back several times to look upon his crumpled body, it had a magnetic pull for me.

\section{A.2. Victim perspective}

It was a rainy autumn day. Fog lay over the fields, but the sun was bright behind the sheen of white fog. The drizzle came through my clothing and I shivered a little. I trod through the forest, feeling the soft leaves give way, and hearing the twigs snap underfoot. I was on the way from our camp back home, and was thinking happily about how I would soon see my wife again. I was pleasantly absorbed in these thoughts. After a few more meters I heard steps behind a ridge up ahead, and then saw a man emerge before me. This was the first and last time I would encounter him. He was a soldier. I could see it in his face. It was expressionless and unshaven. He wore an olive colored rain jacket and heavy, clay caked boots. As he came nearer I could smell the sweat and dirt of his body, he had obviously had a long day behind him. As a watched him, the experiences of the last few days went through my head again, as the soldiers attacked villages. This soldier reminded me of a man, who had killed a neighbor as he tried to hide from them. My body began to shake. That fearful feeling came through me again. In such moments, my senses sharpened and I became aware of my own heavy breath. I saw the pictures before my eyes of those people the soldiers had chased until they were exhausted, their death rattle as their wounds bled out and they died. It terrified me. That feeling that overwhelmed me at this moment is like nothing else. It was pure terror. In this moment he drew out his rifle and smashed the gunstock with full force against my jaw, which gave way with a dull moist crack. I dropped to my knees. My panicked and broken cry was the only thing that I could hear now apart from my breathing. My head was empty and clear. The only thing that came to my conscious ness was the cruel look on his face and how I needed to get away from this. His wide open eyes were filled with an indescribable blackness. I could not turn away from this sight although I wanted to. Warm blood ran from my shattered face and I could see the hot breath climbing into the cold air. I had the feeling that every muscle fiber in my body was electrified. I felt overwhelming horror, as if I was on a powerful drug. Then I nothing could hold me back any longer. The butt of his rifle smashed into my body over and over again. I was broke to pieces. Everything around me melted away in this moment. There was only him and me and nothing that could stop him. I felt the cold steel of his rifle butt against my flesh and agonizing pain in my guts. I could not defend myself and was easy to hit. I was absolutely still for a long time before he let off. I saw his face one more time. I became unconscious and he must have left me lying there at this point. As I came to everything was still. My hair and clothing were soaked with blood, and my body was crumpled. Everything around me was still.

\section{A.3. Bystander perspective}

It was a rainy autumn day. Fog lay over the fields, but the sun was bright behind the sheen of white fog. It was the sort of weather where drizzle came through your clothing causing you to shivere a little. When you tread through the forest, you feel the soft leaves give way, and hear the twigs snap underfoot. On this day two men, a soldier and a farmer, were on the way back home, when they encountered each other. They were both thinking happily about how they would soon see their wives again. They were both pleasantly absorbed in these thoughts. As they neared each other they both heard each others' steps behind a ridge, and then they emerged before each other. This was the first and last time they would encounter each other. They could see each others' faces. They were both expressionless and unshav en. They both wore olive colored rain jackets and heavy, clay caked boots. As they came nearer to each other they could each smell the sweat and dirt of each others' body, they had both obviously had a long day behind him. As they watched each other, the experiences of the last few days went through their heads again, as the soldiers attacked villages. They both had an incident in their heads, of a farmer killed in his house after he tried to hide from the soldiers. Their bodies began to shake. For the soldier it was an intoxicating feeling, for the farmer terrifying. Both men experienced a sharpening of the senses and became aware of their own heavy breath. They saw the pictures before their eyes of those people who had been chased until they were exhausted, their death rattle as their wounds bled out and they died. It excited the soldier and terrified the farmer. That feeling that overwhelmed them at this moment is like nothing else. In this moment the soldier drew out his rifle and smashed the gunstock with full force against the farmer's jaw, which gave way with a dull moist crack. The farmer dropped to his knees. His panicked and broken cry was the only thing that that could be heard now apart from the breathing. Their heads were empty and clear. The only thing that came to their consciousness was the look on the face of the other. Their wide open eyes were filled with an indescribable blackness. They could not turn away from this scene. Warm blood ran from the farmer's shattered face and they could see his hot breath climbing into the cold air. They both had the feeling that every muscle fiber in their bodies was electri fied. It was as if they were on a powerful drug. Then nothing could hold the soldier back any longer. The butt of his rifle smashed into the farmer's body over and over again. He broke to pieces. Everything around them melted away in this moment. There was only the soldier and the farmer and nothing that could stop this scene. The gun met the soft resistance of his flesh under his clothing and the bones broke. The farmer could not defend himself and was easy to hit. He was abso lutely still for a long time before the soldier let off. They saw each other's faces one more time. The farmer's hair and his clothing were soaked with blood. Everything around them was still. The soldier walked away from the unconscious farmer as he lay there, but then turned back several times to look upon his crumpled body, it had a magnetic pull for the soldier.

\section{References}

Akaike, H. (1987). Factor analysis and AIC. Psychometrika, 52(3), 317-332.

Alexander, G. M., Packard, M. G., \& Hines, M. (1994). Testosterone has rewarding affective properties in male rats: Implications for the biological basis of sexual motivation. Behavioral Neuroscience, 108(2), 424-428.

Anderson, C. A., \& Bushmann, B. J. (1997). External validity of 'trivial' experiments: The case of laboratory aggression. Review of General Psychology, 1(1), 19-41. 
Archer, J., \& Mehdikhani, M. (2003). Variability among males in sexually-selected attributes. Review of General Psychology, 7, 219-236.

Archer, J., \& Parker, S. (1994). Social representations of aggression in children. Aggressive Behavior, 20, 101-114.

Arnedo, M. T., Salvador, A., Martínez-Sanchis, S., \& Pellicer, O. (2002). Similar rewarding effects of testosterone in mice rated as short and long attack latency individuals. Addiction Biology, 7, 373-379.

Barker, E. D., Tremblay, R. E., Nagin, D. S., Vitaro, F., \& Lacourse, E. (2006). Development of male proactive and reactive physical aggression during adolescence. Journal of Child Psychology and Psychiatry, 47(8), 783-790.

Bettencourt, B.A., \& Miller, N. (1996). Gender differences in aggression as a function of provocation: A meta-analysis. Psychological Bulletin, 119(3), 422-427.

Blair, R. J. R. (2004). The roles of orbital frontal cortex in the modulation of antisocial behavior. Brain and Cognition, 55, 198-208.

Bluemke, M., Friedrich, M., \& Zumbach, J. (2009). The influence of violent and nonviolent computer games on implicit measures of aggressiveness. Aggressive Behavior, 35, $1-13$

Bradley, M. M., Codispoti, M., Cuthbert, B. N., \& Lang, P. J. (2001). Emotion and motivation I: Defensive and appetitive reactions in picture processing. Emotion, 1(3), 276-298.

Bradley, M. M., \& Lang, P. J. (1994). Measuring emotion: The self-assessment manikin and the semantic differential. Journal of Behavior Therapy and Experimental Psychiatry, 25, 49-59.

Brower, K. J. (1992). Anabolic steroids. Addictive, psychiatric, and medical consequences. The American Journal on Addictions, 1(2), 100-114.

Brower, K. J., Blow, F. C., Young, J. P., \& Hill, E. M. (1991). Symptoms and correlates of anabolic-androgenic steroid dependence. British Journal of Addiction, 86(6), 759-768.

Bushmann, B. J. (1995). Moderating role of trait aggressiveness in the effects of violent media on aggression. Journal of Personality and Social Psychology, 69(5), 950-960.

Cahill, L., Biabinsky, R., Markowitsch, H. J., \& McGaugh, J. L. (1995). The amygdala and emotional memory. Nature, 377, 295-296.

Cahill, L., Haier, R. J., Fallon, J., Alkire, M. T., Tang, C., \& Keator, D. (1996). Amygdala activity at encoding correlated with long-term, free recall of emotional information. PNAS, 93, $8016-8021$.

Carré, J. M., McCormick, C. M., \& Hariri, A.R. (2011). The social neuroendocrinology of human aggression. Psychoneuroendocrinology, 36, 935-944.

Carré, J. M., Putnam, S. K., \& McCormick, C. M. (2009). Testosterone responses to competition predict future aggressive behaviour at a cost to reward in men. Psychoneuroendocrinology, 343, 561-570.

Choi, P. Y. L., Parrott, A.C., \& Cohen, D. (1990). High-dose anabolic steroids in strength athletes: Effects upon hostility and aggression. Human Psychopharmacology, 5, 349-356.

Daly, M., \& Wilson, M. (1996). Homicidal tendencies. Demos, 8, 39-45.

De Beun, R., Jansen, E., Slangen, J. L., \& Van De Poll, N. E. (1992). Testosterone as appetitive and discriminative stimulus in rats: Sex- and dose-dependent effects. Physiology $\varepsilon$ Behavior, 52, 629-634.

Dodge, K. A., Lochman, J. E., Harnish, J.D., \& Bates, J. E. (1997). Reactive and proactive aggression in school children and psychiatrically impaired chronically assaultive youth. Journal of Abnormal Psychology, 106, 37-51.

Duntley, J. D., \& Buss, D. M. (2005). The plausibility of adaptations for homicide. The structure of the innate mind, 291-304.

Duntley, J.D., \& Buss, D.M. (2011). Homicide adaptations. Aggression and Violent Behavior $16,399-410$.

Eagly, A. H., \& Steffen, V. J. (1996). Gender and aggressive behavior: A meta-analytic review of the social psychological literature. Psychological Bulletin, 100(3), 309-330.

Elbert, T., Rockstroh, B., Kolassa, T., Schauer, M., \& Neuner, F. (2006). The influence of organized violence and terror on brain and mind - A co-constructivist perspective. In $\mathrm{P}$. B. Bates, P. A. Reuter-Lorenz, \& F. Rösler (Eds.), Lifespan development and the brain: The perspective of biocultural co-constructivism (pp. 326-363). Cambridge: CUP.

Elbert, T., Weierstall, R., \& Schauer, M. (2010). Fascination violence: On mind and brain of man hunters. European Archives of Psychiatry and Clinical Neuroscience. 260(2), 100-105.

Faul, F., Erdfelder, E., Lang, A. G., \& Buchner, A. (2007). G*Power 3: A flexible statistical power analysis for the social, behavioral, and biomedical sciences. Behavior Research Methods, 39(2), 175-191.

Fox, E., Russo, R., Bowles, R., \& Dutton, K. (2001). Do threatening stimuli draw or hold visual attention in subclinical anxiety? Journal of Experimental Psychology: General, 130, 681-700.

Gault, B.A., \& Sabini, J. (2000). The roles of empathy, anger, and gender in predicting attitudes toward punitive, reparative, and preventative public policies. Cognition and Emotion. Special Issue: Emotion, Cognition, and Decision Making, 14, 495-520.

Hamm, A. O., Cuthbert, B. N., Globisch, J., \& Vaitl, D. (1997). Fear and startle reflex: Blink modulation and autonomic response patterns in animal and mutilation fearful subjects. Psychophysiology, 34, 97-107.

Hecker, T., Hermenau, K., Maedl, A., Elbert, T., \& Schauer, M. (2012). Appetitive aggression in former combatants - Derived from the ongoing conflict in DR Congo. Internationa Journal of Law and Psychiatry, 35(3), 244-249.

Johnson, L. R., \& Wood, R. I. (2001). Oral testosterone self-administration in male hamsters. Hormones and Behavior, 73, 285-292.
Keenan, K., \& Hipwell, A. E. (2005). Preadolescent clues to understanding depression in girls. Clinical Child and Family Psychology Review, 8(2), 89-105.

Klinesmith, J., Kasser, T., \& McAndrew, F. T. (2006). Guns, testosterone, and aggression: An experimental test of a mediational hypothesis. Psychological Science, 17, 568-571.

Knickmeyer, C., \& Baron-Cohen, S. (2006). Topical review: Fetal testosterone and sex differences in typical social development and in autism. Journal of Child Neurology, $21,825-845$

Lang, P. J., Bradley, M. M., \& Cuthbert, B. N. (1997). Motivated attention: Affect, activation and action. In P. J. Lang, R. F. Simons, \& M. T. Balaban (Eds.), Attention and orientating: Sensory and motivational processes (pp. 97-135). Mahwah, New Jersey: Lawrence Erlbaum.

Lang, P. J., Bradley, M. M., \& Cuthbert, B. N. (2008). International Affective Picture System (IAPS): Affective ratings of pictures and instruction manual. Technical Report A-8. Gainesville, FL: University of Florida.

Lewinsohn, P.M., Gotlib, I. H., Lewinsohn, M., Seeley, J. R., \& Allen, N.B. (1998). Gender differences in anxiety disorders and anxiety symptoms in adolescence. Journal of Abnormal Psychology, 107, 109-117.

Linz, D., Donnerstein, E., \& Adams, S. M. (1989). Physiological desensitization and judgments about female victims of violence. Human Communication Research, 15(4), 509-522.

Maclure, R., \& Denov, M. (2006). "I didn't want to die so I joined them": Structuration and the process of becoming boy soldiers in Sierra Leone. Terrorism and Political Violence, 18, 119-135. http://dx.doi.org/10.1080/09546550500384801.

Maner, J. K., Miller, S. L., Schmidt, N.B., \& Eckel, L. A. (2008). Submitting to defeat: Social anxiety, dominance threat, and decrements in testosterone. Psychological Science, 19, 764-768.

Mehta, P. H., \& Josephs, R. A. (2006). Testosterone change after losing predicts the decision to compete again. Hormones and Behavior, 50(5), 684-692.

Nell, V. (2006). Cruelty's rewards: The gratifications of perpetrators and spectators. Behavioral and Brain Sciences, 29, 211-257.

Parrott, A.C., Choi, P. Y. L., \& Davies, M. (1994). Anabolic steroid use by amateur athletes: Effects upon hostility and aggression. The Journal of Sports Medicine and Physical Fitness, 34(3), 292-298.

Peters, K. D., \& Wood, R. I. (2005). Androgen dependence in hamsters: Overdose, tolerance, and potential opioidergic mechanisms. Neuroscience, 130(4), 971-981.

Renfrew, J. W. (1997). Aggression and its causes. A biopsychosocial approach. New York: Oxford University Press.

Richtelin, J., Richardson, D. S., \& Mason, G. D. (2010). Predictive validity of IAT aggressiveness in the context of provocation. Social Psychology, 41(1), 27-34.

Schauer, M., \& Elbert, T. (2010). Dissociation following traumatic stress: Etiology and treatment. Journal of Psychology, 218, 109-127.

Siegel, A., Roeling, T. A., Gregg, T. R., \& Kruk, M. R. (1999). Neuropharmacology of brainstimulation-evoked aggression. Neuroscience and Biobehavioral Reviews, 23, 359-389.

Stein, D. J. (2000). The neurobiology of evil: Psychiatric perspectives on perpetrators. Ethnicity \& Health, 5, 305-315.

Su, T. P., Pagliaro, M., Schmidt, P. J., Pickar, D., Wolkowitz, O., \& Rubinow, D. R. (1993). Neuropsychiatric effects of anabolic steroids in male normal volunteers. JAMA, 269 (21), 2760-2764.

Tedeschi, J. T., \& Felson, R. B. (1995). Violence, aggression, and coercive actions. Washington, DC: APA.

Van Goozen, S. H. M., Cohen-Kettenis, P. T., Gooren, L. J. G., Frijda, N. H., \& Van Der Poll, N. E. (1995). Gender differences in behaviour: Activating effects of cross-sex hormones. Psychoneuroendocrinology, 20(4), 343-363.

Vitiello, B., \& Stoff, D.M. (1997). Subtypes of aggression and their relevance to child psychiatry. Journal of the American Academy of Child and Adolescent Psychiatry, 36(3), 307-315.

Weierstall, R., \& Elbert, T. (2011). The Appetitive Aggression Scale. European Journal of Psychotraumatology, 2, 8430. http://dx.doi.org/10.3402/ejpt.v2i0.8430.

Weierstall, R., Huth, S., Knecht, J., Nandi, C., \& Elbert, T. (2012). Attraction to violence as a resilience factor against trauma disorders: Appetitive aggression and PTSD in German World War II veterans. PLOS ONE, 7(12), e50891. http://dx.doi.org/10.1371/journal. pone.0050891.

Weierstall, R., Schaal, S., Schalinski, I., Dusingizemungu, J. -P., \& Elbert, T. (2011). The thrill of being violent as an antidote to posttraumatic stress disorder in Rwandese genocide perpetrators. European Journal of Psychotraumatology, 2, 6345. http://dx.doi.org/10.3402/ejpt.v2i0.6345.

Weierstall, R., Schalinski, I., Crombach, A., Hecker, T., \& Elbert, T. (2012). When combat prevents PTSD symptoms - Results from a survey with former child soldiers in Northern Uganda. BMC Psychiatry, 12, 41. http://dx.doi.org/10.1186/ 1471-244X-12-41.

Weiger, W. A., \& Bear, D.M. (1988). An approach to the neurology of aggression. Journal of Psychiatry Research, 22, 85-98.

Wood, R. I. (2002). Oral testosterone self-administration in male hamsters: Doseresponse, voluntary exercise, and individual differences. Hormones and Behavior, 41, $247-258$.

Wood, R. I. (2008). Anabolic-androgenic steroid dependence? Insights from animals and humans. Frontiers in Neuroendocrinology, 29(4), 490-506.

Yiend, J., \& Matthews, A. (2001). Anxiety and attention to threatening pictures. The Quarterly Journal of Experimental Psychology, 54(3), 665-681. 